\title{
5
}

\section{Information technology in educational management of tomorrow's school}

\section{Telem}

School of Education, Tel Aviv University, Tel Aviv, Israel

Phone: (972)-3-6407123

e-mail:telem@post.tau.ac.il

Fax: (972)-3-6409477

\section{B.Z. Barta}

Ministry of Education

Culture and Sports, Jerusalem, Israel

Phone: (972)-4-353755 Fax: (972)-4-353754

e-mail:ben@actcom.co.il

K.D. Levin

College of Management, Tel Aviv, Israel

Phone: (972)-3-6990444 Fax: (972)-3-6990454

e-mail:levind@technion.ac.il

\begin{abstract}
The main principles of Sizer's "Coalition of essential schools" project in the US, and Chen's "Kramim school" project in Israel, two "school of the future" projects, are presented. ITEM's possible contribution to each of their principles is exemplified. It is argued that ITEM is indispensable in the school of the future, especially as a tool for enhancing school leadership, change introduction and management and, for teaching and learning evaluation. The "school of the future" still has to evolve and current ITEM systems will have to be redesigend to serve its emerging pedagogical and administrative needs.
\end{abstract}

Keywords

Educational management, information technology, evaluation, school leadership 


\section{INTRODUCTION}

The current dissatisfaction with the way schools operate (Goodlad, 1991; Sarason, 1990; Sizer, 1984, 1993) has resulted in a search for a new type of school - the "school of the future". So far however there is no agreement on the nature and structure of this school. For example, some information technology oriented scholars envision a "virtual school", very unlike today's school. Students in this school would not have (partly or at all) to attend classes the way they do now. They will study at their own pace, mainly from their homes, via computers linked up with educational databases. Currently we have a long way to go to this disputable "virtual school" model. Rather than looking this far out into the future, this paper discusses the role of information technology in educational management (ITEM) in the school of the future by relating to two innovative projects: a) Professor Theodor Sizer's "Coalition of essential schools" project, already encompassing about 180 high-schools, whose principles are widely accepted in the USA, and b) the "Kramim school" project, headed by Professor David Chen (1995), established as part of the school of the future project in Israel.

\section{MAIN PRINCIPLES WITH EXAMPLES OF ITEM'S POSSIBLE ROLE}

According to Sharan (1995) Sizer's project has the following five main features:

1. The school is viewed as a community in which systematic teamwork and teachers' collaboration should contribute to both students and teachers on the instructional as well as the social level, (Bryk and Driscoll, 1988; Little, 1987; Murphy, 1991; Sarason, 1993). Many school decisions are group-based (Telem, 1990a). For instance, reviewing a particular student's achievements throughout the term, a decision on students' transfer between "houses" (see ahead). Instructional strategies should be tailored to the needs of the student.

Examples of ITEM's role: 1. Groupware software packages (e.g., Lotus "Notes") which enable collaborative work among teachers and/or various other school employees (e.g., principal, counselor, subject-matter coordinators, homeroom teachers, grade-level coordinators), by creating and sharing various types of data (such as relational databases, word processing documents, spreadsheets, email) in a shared database, hold significant promise for improving teamwork in schools. 2. In a high-school where ITEM operated successfully it was found to encourage teamwork among teachers teaching the same subject, collaboration in preparing lesson-plans, teaching materials and tests, and in dealing jointly with issues arising from ITEM's reports (Telem and Avidov, 1996).

2. An integrative curriculum with a reduced number of subjects in three to four knowledge areas of significance to students' life.

3. Tighter interrelations between school and community. Part of the learning should take place at various community sites (such as government agencies, district public services, industry, commerce, banking, transportation). For example, in Sizer's project, students serve in such community sites half a day, once per week.

Example of ITEM's role: Handling, follow-up and evaluation of studentcommunity interrelations as well as the management and control of the non-school sites (i.e., in the community) learning activities, should be effectively undertaken by ITEM. 
4. Frontal instruction should be minimized and replaced by activities such as project preparation, social systems simulations, etc. For example, in Sizer's project students investigate phenomena in nature, society and the world, and simulate situations in which they act as professionals.

Example of ITEM's role: When needed, the school's database should be expanded to enable handling, follow-up and evaluation of these activities.

5. Tighter teacher-student relations, where each student is personally recognized by at least one teacher.

Example of ITEM's role: Present schools' database should be expanded to provide information on these tightened student-teacher relations including "soft information" (i.e., non-factual information such as counselor's opinions, reports and explanations expressed in text form), for instance, teachers' opinions on students, students explanations for their absenteeism.

According to Chen (1995), the following basic assumptions underlying the traditional school (T) should be replaced in the school of the future $(\mathbf{F})$ :

1. T: Human knowledge is linear, and hence both structure and organization of learning should be linear too.

F: Human knowledge is complex (e.g., network, tree-shaped). The learning organization should match this.

Example of ITEM's role: ITEM's computer managed instruction (CMI) module (Telem, 1982) should be developed to serve these complex structures of learning.

2. T: Human knowledge is universal and relatively static. A curriculum that represents the study "discipline" is therefore needed.

F: Knowledge is dynamic and inter-disciplinary. As a result, curricula keep rapidly changing quantitatively and qualitatively.

Example of ITEM's role: When needed, ITEM's CMI module should be adjusted to support this on-going rapid quantitative and qualitative change.

3. T: Human knowledge is standard. Therefore, all students should use the same textbooks in order to achieve this knowledge.

F: Human knowledge is pluralistic and relative and therefore should be adjusted to each student's personality.

Examples of ITEM's role: ITEM's CMI module should be expanded to monitor each student's progress in any course/subject of study, providing him/her with a pluralistic choice of textbooks, exercises, etc.

4. T: The site of learning is exclusively the school.

F: Students encounter new knowledge and learn anywhere.

Example of ITEM's role: An effective management of the non-school sites learning activities.

5. T: A fixed relation exists between time and learning: The more the student studies the more knowledge s/he gains. Therefore, fixed time units such as a class, study day, semester, academic year, etc. are used. As a result, time resources are inefficiently used. According to Chen (1995, p. 93), only about $12 \%$ of the time resources are allocated to institutionalized, controlled studies.

F: Time resources should be used in a more effective manner.

Example of ITEM's role: ITEM should be redesigend to provide school employees with information on "time consumption", thus enabling a more flexible/effective use of time. For instance, changes in the length of the school day, changes in the structure of studies. 
6. T: The class, i.e., 30 to 40 students and one teacher, constitutes the basic organizational unit. Classes are assembled into age levels which are assembled into a school.

F: The school should support a flexible and differential study group structure. For example, Sizer overruled the existing conception of "one class one teacher". In his project the high-school encompasses up to 1350 students, divided into "houses" of 210 students with 13 teachers each: Three mathematics and science teachers, three teachers of history and philosophy, three for arts, three general teachers and one additional teacher. They are divided into three sub-groups consisting of one teacher of each of the above disciplines. This structure eliminates organizational barriers between teachers and encourages teamwork and teaching and learning coordination.

Example of ITEM's role: In order to assist both in effective class mapping and construction, and in students' and teachers' placement and on-going evaluation, expert systems and models should be developed and extensively used.

7. T: Policy management and control are carried out according to inputs (e.g., class hours, classes, teachers, teacher training). A direct relation exists between inputs and outputs so that an increase in the former will result in an increase in the latter.

F: Cybernetic management control, i.e., maintaining a course towards a goal through on-going communication, feedback, control and regulation.

Example of ITEM's role: An effective cybernetic management control is virtually impossible without a computerized mechanism, i.e., an ITEM. Real-time feedback on, for example, student/teacher/"home"/etc. achievements, is one of ITEM's strongest advantages.

8. T: Partial development policy i.e., introduction of change/s in one subsystem (e.g., teaching, discipline, evaluation) while ignoring the others.

F: A systems development policy approach should be adopted, implying that a change in one of the school's subsystems affects its other subsystems.

Example of ITEM's role: Since ITEM should be designed a-priori from a systems approach perspective, its contribution toward this aim is paramount. Its integrated, school database as well as its easily and instantly retrieved information, disseminated concurrently to the school's various functionaries, serve both as a systems development approach and as follow up tools. Reliable evaluation in a systems approach mode is possible only through ITEM.

9. T: Reformist strategy of change, seeking to achieve immediate change/s through administrative measures.

F: Experimental along time strategy of change.

Example of ITEM's role: Built in to the experimental strategy is the notion of both on-going data collection and instant feedback mechanisms. ITEM is an ideal tool for achieving this strategy in various domains such as "home" construction, student/teacher evaluation, etc.

\section{LEADERSHIP, LEARNING AND INSTRUCTION EVALUATION}

In the "school of the future" the principal's role as a school leader is of major importance. Taking into account Sizer's and Chen's above mentioned assumptions, teaching and learning evaluation will be shaped differently in this school. Therefore, ITEM should be designed "to match the structure, management tasks, instructional processes and special needs of the school [of the future] ... [It] is not a means in itself. It is a computer-based artificial technological system ... providing decision support to the 
decision system that is a regular part of organizational management" (Telem, 1994, p. 2828). According to Telem (1990a,b) ITEM provides information on "what has happened" and on "what would happen". It incorporates model formation, expert systems, text manipulation, and soft information handling. However, to comply with the emerging needs of the school of the future, ITEM's information needs should be redefined and its database redesign. ITEM is an indispensable mechanism for both pedagogical and administrative decision making and leadership.

\subsection{ITEM and the principal as a school leader}

Special emphasis is allocated in the school of the future to the principal as a school and change leader. As such, s/he should be capable of leading individuals and groups and of planning change projects. S/he has to set objectives, fix priorities (relating to students, teachers and the community), present objectives and change plans to school employees, identify discrepancies between present and required situations, and allocate resources for achieving school objectives and change (Sharan, 1995). The information provided by ITEM is a tool for achieving these tasks. It has already been found that in high-schools where ITEM operates effectively, principals use it as a pedagogical leadership tool (Telem and Buvilski, 1995; Telem and Avidov, 1994, 1996).

The problem solving process includes the identification of relevant information and its analysis. Information retrieved from ITEM's integrative, overall and updated database should serve the principal in his/her systematic analysis of problems and achievement of good solutions, as well as for strategic school planning. As Telem and Buvilski (1995) showed, principals do use ITEM for making strategic decisions and for physical and human resource allocation. They also showed that ITEM provides the principal with ongoing feedback (i.e., a cybernetic process) on the pedagogical and administrative activities taking place in school. In Sizer's project the team in each house is authorized to make most of the organizational and pedagogical decisions related to the work in their house. This team is also responsible for controlling performance and for closing gaps between plans and performance. The information provided by ITEM should serve as a major tool for this purpose too.

\subsection{Evaluation}

On-going evaluation is of major importance in the school of the future. According to Sizer, external examinations (e.g., matriculation examinations) should be eliminated, while the amount of internal examination should also be reduced to a minimum. Evaluation of students' cognitive skills over long periods of time in different situations and by different tools, will replace answers to test questions at a given date and time. Written examinations will be replaced by evaluation of students' exhibits and portfolios (cf. Barone, 1991). Lectures will be minimized and replaced by students' involvement in the process of learning, mainly by self-achievement and use of knowledge. As such, evaluation will become significantly more complex than the evaluation of written tests which is currently common. According to Sharan (1995) evaluation in the school of the future should encompass qualities such as clear oral and written presentation (through various means e.g., drawing), sophistication (e.g., well informed and perceptive use of sources) logic, organization and congruence between the various parts of the presentation. ITEM should be developed to constitute a major tool in the reshaped evaluation process. It has already been found that principals and subject-coordinators do use ITEM for evaluating student/class's achievements and teachers' work (Telem and Buvilski, 1995; Telem and Avidov, 1994, 1996). 


\section{CONCLUSION}

ITEM will constitute an indispensable tool in the school of the future. Whatever form and structure the school will take, on-going information retrieval and distribution (on learning, teaching, school site and finance, plan versus performance etc.) to school community members, is of major importance. As future schools will metamorphose, present ITEMs will have to be redesign to serve their new pedagogical and administrative needs, while also adapting themselves to on-going hardware and software innovations.

\section{REFERENCES}

Barone, T. (1991) Assessment as theater: staging an exposition. Educational Leadership, February, 47-59.

Bryk, A. and Driscoll, M. (1988) The high school as community: contextual influences and consequences for students and teachers. National Center on Effective Schools, Madison, Wisconsin.

Chen, D. (1995) "Kramim" school in Rishon-Lezion: principles and planning of an innovative model in education, in Education Toward the Twenty First Century (ed. D. Chen), Ramot, Tel-Aviv (Hebrew)

Goodlad, J. (1991) Why we need a complete redesign of teacher education. Educational Leadership, 49, 4-6.

Little, J.W. (1987) Teachers as colleagues, in Educators' handbook: A research perspective (ed. V. Richardson-Koehler), Longman, New York.

Murphy, J. (1991) Restructuring schools. Teachers College, New York.

Sarason, S. (1990) The predictable failure of educational reform. Jossey-Bass, San Francisco.

Sarason, S. (1993) The case for change: rethinking the preparation of educators. JosseyBass, San Francisco.

Sharan, S. (1995) The innovative high school: structure, administration and teaching, in Education toward the twenty first century (ed. D. Chen), Ramot, Tel-Aviv (Hebrew).

Sizer, T. (1984) Horace's compromise: The dilemma of the American high school. Houghton-Mifflin, Boston.

Sizer, T. (1993) Horace's school: redesigning the American high school. HoughtonMifflin, Boston.

Telem, M. (1982) The CMI and the MIS - an integration needed. AEDS Journal, 16(1), 48-55.

Telem, M. (1990a) DSS in educational organizations. Computers and Education, 14(1), 61-69.

Telem, M. (1990b) Educational DSS: potential services, benefits, difficulties, and dangers. Computers and Education, 14(1), 71-80.

Telem, M. (1994) Information technology use in educational management systems. The International Encyclopedia of Education (2nd Ed), 5, 2828-2831.

Telem, M., and Avidov, O. (1994) Management information system (MIS) impact on the loosely coupled nature of a high-school: a case study. Planning \& Changing, 25(3/4), 192-205.

Telem, M., and Avidov, O. (1996) School management information systems and the loosely coupled nature of a high-school instruction administration subsystem - a preliminary study. Journal of Research on Computing in Education, 28(2), 258269.

Telem, M., and Buvilski, T. (1995) The potential impact of information technology on the high-school principal's role - a preliminary exploration. Journal of Research on Computing in Education, 27(3), 281-296. 


\section{BIOGRAPHIES}

Moshe Telem, Chair of the educational administration program in the School of Education, Tel Aviv University, received his doctorate from the Hebrew University in Jerusalem. He specializes in MIS in education and educational administration.

Ben Zion Barta received his Ph.D. from Technion Israel. As Chief Inspector for Computers in Education in the Ministry of Education, he is in charge of the coordination of R\&D projects and the implementation of computer education activities in the Israeli school system.

K. Dan Levin has served on the faculties of the Wharton School of Business at the University of Pennsylvania and at the School of Management of Tel Aviv University. He is currently at Tel Aviv College of Management. 